\title{
Impact of metabolic disorders on endometrial receptivity in patients with polycystic ovary syndrome
}

\author{
CAN WANG, YANG-XING WEN and QING-YUN MAI \\ Reproductive Medicine Center, The First Affiliated Hospital, Sun Yat-Sen University, \\ Guangzhou, Guangdong 510080, P.R. China
}

Received November 12, 2021; Accepted December 22, 2021

DOI: $10.3892 /$ etm.2022.11145

\begin{abstract}
The present study investigated the expression of endometrial receptivity-related molecules in patients with polycystic ovary syndrome (PCOS) and different androgen status, insulin resistance (IR) levels, and body mass indexes (BMI) to identify the mechanism underlying their effects on pregnancy outcomes. The present study recruited 43 participants from November 2020 to January 2021, which were classified into five groups: i) Hyperandrogenemia (HA) combined with impaired glucose tolerance group $(n=8)$; ii) HA combined with diabetes mellitus group $(\mathrm{n}=8)$; iii) HA combined with non-IR (NIR) group ( $\mathrm{n}=10)$; iv) non-HA (NHA) androgen combined with IR group ( $\mathrm{n}=8)$; and $\mathrm{v}$ ) NHA combined with NIR group $(n=9)$. In addition, according to their BMIs, patients were sub-grouped into lean/normal $(n=27)$, overweight $(n=8)$ or obese $(n=8)$ groups. The mRNA expression levels of endometrial receptivity-related molecules were detected using reverse transcription-quantitative PCR. In addition, flow cytometry was used to determine the phenotype and percentage of uterine natural killer cells (uNK). According to the results, patients with PCOS and IR status, HA and obesity (BMI $\geq 24 \mathrm{~kg} / \mathrm{m}^{2}$ ) demonstrated significantly decreased mRNA expression levels of adiponectin, adiponectin receptor (AdipoR)1, AdipoR2, adapter protein containing PH domain, PTB domain and leucine zipper motif 1 , estrogen receptor (ER) $\alpha, E R \beta$, progesterone receptor (PR), IL-15, integrin $\beta 3$ av $\beta 3$, and insulin-like growth factor binding protein-1, but increased mRNA expression levels of IL-6 and IL-8 compared with NHA + NIR group or lean/normal group, respectively. In addition, obese patients with PCOS demonstrated increased mRNA expression levels of PR compared with overweight patients. This suggested that insulin resistant status, HA, and obesity could alter the
\end{abstract}

Correspondence to: Professor Qing-Yun Mai, Reproductive Medicine Center, The First Affiliated Hospital, Sun Yat-Sen University, 58 Zhongshan Road II, Guangzhou, Guangdong 510080, P.R. China

E-mail: maiqy@mail.sysu.edu.cn

Key words: polycystic ovary syndrome, hyperandrogen status, insulin resistance, obesity, endometrial receptivity endometrial receptivity of patients with PCOS, which may explain poorer embryo implantation and pregnancy outcomes in clinics.

\section{Introduction}

Polycystic ovary syndrome (PCOS) is the most common reproductive endocrine and metabolic disease with a prevalence of $4-10 \%$ in reproductive-age women globally (1). The main manifestations of the disease are oligomenorrhea, chronic anovulation, polycystic ovarian ultrasonography changes and clinical or biochemical hyperandrogenism. Reportedly, $50-60 \%$ of patients with PCOS have different degrees of hyperandrogenemia (HA) (2), and $44-70 \%$ of patients have insulin resistance (IR) and hyperinsulinemia (3-5). In addition, $44-70 \%$ of patients with PCOS are obese (6). Although identification of the mechanism of PCOS remains elusive, the interaction of genetic, endocrine and environmental factors likely leads to PCOS (7).

In recent years, an increasing number of studies have confirmed that androgen status, IR and obesity play notable roles in the pathogenesis of PCOS (8-10). Previous studies have suggested that hyperandrogen status $(11,12)$, IR $(13-15)$ and obesity (16-19) increase the rate of miscarriage and decrease the pregnancy rate among patients with PCOS. Chang et al (13) indicated that IR affects endometrial function and the implantation process. Patel and Carr (20) revealed that hyperandrogen status and IR are associated with adverse fertility outcomes in patients with PCOS. Cohort studies of $>9,500$ cycles (21-23), indicate that obesity may induce embryo implantation failure by impairing endometrial receptivity.

Endometrial receptivity is an important factor for successful embryo implantation, which is accompanied by the fluctuations of steroid hormones and endometrial receptivity-related factors, the influx of uterine natural killer cells (uNK) cells and the inhibition of inflammatory factors. Endometrial receptivity is regulated by multiple factors, such as receptors of hormones (estrogen and progesterone), pro-inflammatory cytokines [IL-6, IL-8, IL-15 and monocyte chemoattractant protein-1 (MCP-1)] and endometrial decidualization-related factors [integrin $\beta 3(\operatorname{av} \beta 3)$ and insulin-like growth factor binding protein-1 (IGFBP-1)] (24).

In addition, adiponectin is also a biomarker of endometrial receptivity $(25,26)$. Adiponectin, an insulin sensitizer secreted 
by adipocytes, is closely associated with the insulin signal transduction pathway $(25,26)$. Adiponectin exerts its effects by binding to adapter protein containing PH domain, PTB domain and leucine zipper motif 1 (APPL1), together with AdipoR1 and AdipoR2, to activate different signaling pathways, such as MAPK, p38, ERK1/2, Akt and AMP-activated protein kinase (AMPK) (27). Adiponectin contains three main forms: Trimer, hexamer and high molecular weight (HMW). Some studies hypothesize that HMW adiponectin is the form most closely associated with insulin sensitivity (28). The binding of the APPL1 to adiponectin receptors is regulated by the APPL2; AdipoR1- and R2-dependent signaling is mediated through APPL 1 and APPL2. In the absence of adiponectin signal, APPL2 can bind to the adiponectin receptors or it can form an APPL1/APPL2 heterodimer which prevents the binding of APPL1/adiponectin receptors (29). The adiponectin signaling pathways play notable roles in anti-atherosclerosis, improving the insulin resistant state, reducing blood glucose and reducing anti-inflammatory effects.

Metabolic disorders (high androgen status, IR and obesity) may be the reason for embryo implantation failure, as androgen status and IR are two interacting factors. However, previous studies $(13,21-23,30)$ did not assess different androgen status combining with different IR levels, nor consider the BMI cutoff value for Asian PCOS women. In addition, the majority of previous studies were performed in spontaneous ovulation. Therefore, based on previous findings $(24,25)$ the present study investigated the endometrial receptivity in patients with PCOS with different metabolic abnormalities by assessing well-characterized endometrial receptivity markers, including adiponectin and its signaling protein, pro-inflammatory cytokines (MCP-1, IL-6 and IL-8) mediated through adiponectin, estrogen receptor $(\mathrm{ER} \alpha), \mathrm{ER} \beta$, progesterone receptor (PR), IL-15, av $\beta 3$ and IGFBP-1 in the endometrium during the window of implantation.

\section{Materials and methods}

Ethical approval. The present study was approved by the Clinical Scientific Research and Experimental Animal Ethics Committee of the First Affiliated Hospital of Sun Yat-sen University [approval no. Ethics (2020) no. 422-1]. Written informed consent was obtained from all participants.

Participants. Infertile patients with PCOS attending the Department of Reproductive Endocrine of the First Affiliated Hospital of Sun Yat-sen University (Guangzhou, China) from November 2020 to January 2021 were recruited. The patients' PCOS diagnoses were based on the 2003 Rotterdam criteria (31). Each participant met at least two of the following criteria: i) Oligomenorrhea and/or chronic anovulation; ii) clinical and/or biochemical hyperandrogenism; and iii) polycystic ovarian ultrasonography changes. The exclusion criteria were patients with Cushing's syndrome, congenital adrenal hyperplasia, androgen-secreting tumor, tubal effusion, intrauterine adhesions, multiple endometrial polyps, chromosomal diseases, recurrent fertilization failures, organic diseases of the uterus or ovaries (such as endometriosis or adenomyosis), history of surgery, pelvic radiotherapy and chemotherapy in ovaries, thyroid diseases, hyperprolactinemia, adrenal gland tumors, cardiovascular and cerebrovascular diseases and mental illness and associated disorders. Patients who took hormones or drugs in the past 3 months (that would affect insulin) were also excluded. The diagnosis was confirmed by a pathologist, and the pathologist was independent from the study.

Levels of testosterone (T), sex hormone-binding globulin (SHBG), oral glucose tolerance test (OGTT) and fasting insulin were measured on the 2-5 days of menstruation. High androgen status was determined when the free androgen index (FAI) $(\%)$ [ T (nmol/l)/SHBG (nmol/l)] was $>4.5 \%$ (32). IR was considered when the homeostasis model assessment IR (HOMA-IR) [fasting insulin ( $\mu$ international unit $(\mathrm{IU}) / \mathrm{ml}) \mathrm{x}$ fasting plasma glucose (FPG) $(\mathrm{mmol} / \mathrm{l}) / 22.5]$ was $>2.4$ (33). According to the OGTT test, the present study defined FPG as $\geq 5.6 \mathrm{mmol} / 1$ and/or 2-h postprandial blood glucose (2hPBG) $\geq 7.7 \mathrm{mmol} / 1$ as impaired glucose tolerance (IGT); furthermore, FPG $\geq 7.0 \mathrm{mmol} / 1$ and/or $2 \mathrm{hPBG} \geq 11.1 \mathrm{mmol} / \mathrm{l}$ was defined as diabetes mellitus (34).

The patients were classified into five different groups depending on their FAI, HOMA-IR, and OGTT results: i) Hyperandrogenemia combined with impaired glucose tolerance (HA + IGT) group $(n=8), F A I \geq 4.5 \%$ and HOMA-IR $>2.4$, $5.6 \mathrm{mmol} / 1 \leq \mathrm{FPG} \leq 6.9 \mathrm{mmol} / 1$, and/or $7.7 \mathrm{mmol} / 1 \leq 2 \mathrm{~h}$ PBG $\leq 11 \mathrm{mmol} / \mathrm{l}$; ii) hyperandrogenemia combined with diabetes mellitus $(\mathrm{HA}+\mathrm{DM})$ group $(\mathrm{n}=8)$, FAI $\geq 4.5 \%$, HOMA-IR $>2.4$, FPG $\geq 7.0$ and/or 2 h PBG $\geq 11.1$; iii) hyperandrogenemia combined with non-IR (HA + NIR) group $(n=10)$, FAI $\geq 4.5 \%$, HOMA-IR $\leq 2.4$; iv) non-hyperandrogenemia androgen combined with IR (NHA + IR) group $(\mathrm{n}=8)$, FAI $<4.5 \%$, HOMA-IR $>2.4$; or v) non-hyperandrogenemia combined with non-IR (NHA + NIR) group $(n=9)$, FAI $<4.5 \%$, HOMA $\leq 2.4$. In addition, according to the BMI value, the subjects were divided into a lean/normal group $\left(\mathrm{n}=27 ; \mathrm{BMI}<24 \mathrm{~kg} / \mathrm{m}^{2}\right)$, an overweight group $(\mathrm{n}=8 ; 24 \leq$ BMI $\left.<28 \mathrm{~kg} / \mathrm{m}^{2}\right)$, and an obese group $\left(\mathrm{n}=8 ; \mathrm{BMI} \geq 28 \mathrm{~kg} / \mathrm{m}^{2}\right)(35)$.

Sample collection and treatments. The number of antral follicles was measured by vaginal B-ultrasound on the 2-5 days of menstruation for all participants, and ultrasound examinations were conducted every few days to monitor the number and size of the follicles as well as the endometrial thickness. In addition, the basic information of each patient was collected on the 2-5 days of menstruation, including age, BMI, years of infertility, and blood samples. In this sample, other possible interference in the diagnosis of PCOS [such as follicle-stimulating hormone (FSH), luteinizing hormone (LH), estrogen, progesterone, testosterone, prolactin (PRL), anti-Mullerian hormone (AMH), thyroid-stimulating hormone (TSH), high-density lipoprotein (HDL), low-density lipoprotein (LDL), triglyceride (TG) and cholesterol (CHOL)] were included on Table I.

In order to guarantee the transformation of the endometrium to the secretory phase, hormone replacement therapy (HRT) was performed: $2 \mathrm{mg}$ of estradiol was given daily (Progynova ${ }^{\circledR}$; Bayer) for endometrial proliferation support for $\geq 10$ days. When the endometrium thickness reached $8 \mathrm{~mm}, 10 \mathrm{mg}$ of dydrogesterone tablets were given twice a day (Duphaston ${ }^{\circledR}$; Abbott Biologicals B.V.) for 5 days for endometrial transformation. On the fifth day of endometrial 
Table I. Chemical and endocrine characteristics of the studied groups.

\begin{tabular}{|c|c|c|c|c|c|c|}
\hline Parameters & $\mathrm{HA}+\mathrm{IGT}$ & $\mathrm{HA}+\mathrm{DM}$ & $\mathrm{HA}+\mathrm{NIR}$ & $\mathrm{NHA}+\mathrm{IR}$ & $\mathrm{NHA}+\mathrm{NIR}$ & P-value \\
\hline Number & 8.00 & 8.00 & 10.00 & 8.00 & 9.00 & \\
\hline Age (years) & $25.63 \pm 3.02$ & $26.43 \pm 3.87$ & $28.20 \pm 3.36$ & $26.60 \pm 2.51$ & $28.22 \pm 2.39$ & 0.33 \\
\hline WHR & $0.89 \pm 0.03$ & $0.92 \pm 0.03$ & $0.89 \pm 0.04$ & $0.86 \pm 0.03$ & $0.90 \pm 0.02$ & 0.16 \\
\hline BMI $\left(\mathrm{kg} / \mathrm{m}^{2}\right)$ & $25.05 \pm 3.2$ & $27.45 \pm 5.05$ & $21.25 \pm 1.93$ & $23.37 \pm 3.69$ & $19.11 \pm 2.37^{a}$ & $<0.001$ \\
\hline $\mathrm{FSH}(\mathrm{mIU} / \mathrm{ml})$ & $5.35 \pm 1.60$ & $4.94 \pm 0.91$ & $5.29 \pm 1.29$ & $5.40 \pm 0.64$ & $\begin{array}{c}5.29 \\
(4.68,5.97)\end{array}$ & 0.81 \\
\hline LH (mIU/ml) & $7.26 \pm 4.39$ & $7.53 \pm 2.51$ & $8.68 \pm 4.83$ & $40.94 \pm 11.03$ & $7.58 \pm 3.66$ & 0.76 \\
\hline $\mathrm{E} 2(\mathrm{pg} / \mathrm{ml})$ & $33.75 \pm 9.15$ & $35.3 \pm 10.41$ & $40.81 \pm 17.88$ & $40.94 \pm 11.03$ & $39.49 \pm 15.92$ & 0.86 \\
\hline PRL (ng/ml) & $\begin{array}{c}13.01 \\
(9.29,23.37)\end{array}$ & $17.67 \pm 8.06$ & $\begin{array}{c}15.22 \\
(10.25,27.47)\end{array}$ & $12.41 \pm 5.29$ & $\begin{array}{c}14.39 \\
(12.81,20.96)\end{array}$ & 0.78 \\
\hline $\mathrm{AMH}$ & $11.44 \pm 5.17$ & $7.57 \pm 4.56$ & $11.05 \pm 5.57$ & $\begin{array}{c}10.46 \\
(6.62,11.15)\end{array}$ & $\begin{array}{c}9.04 \\
(6.61,12.97)\end{array}$ & 0.38 \\
\hline TSH & $1.80 \pm 1.11$ & $\begin{array}{c}1.55 \\
(1.25,2.14)\end{array}$ & $2.16 \pm 1.09$ & $1.52 \pm 0.63$ & $1.97 \pm 0.58$ & 0.62 \\
\hline CHOL & $5.15 \pm 0.85$ & $4.9(4.6,5.3)$ & $5.11 \pm 0.99$ & $4.6(4.6,5.95)$ & $4.6 \pm 0.89$ & 0.48 \\
\hline TG & $\begin{array}{c}1.01 \\
(0.89,2.03)\end{array}$ & $1.3 \pm 0.65$ & $1.05 \pm 0.39$ & $1.11 \pm 0.43$ & $0.85 \pm 0.13$ & 0.42 \\
\hline HDL & $1.28 \pm 0.36$ & $\begin{array}{c}1.24 \\
(1.14,1.31)\end{array}$ & $1.54 \pm 0.30$ & $1.35 \pm 0.20$ & $1.40 \pm 0.25$ & 0.34 \\
\hline LDL & $3.29 \pm 0.62$ & $3.22 \pm 0.22$ & $1.54 \pm 0.30$ & $1.35 \pm 0.20$ & $1.40 \pm 0.25$ & 0.22 \\
\hline
\end{tabular}

${ }^{\mathrm{a}} \mathrm{P}<0.05$ compared with HA + IGT. Data are presented as means \pm SEM (normal distribution) or as medium (interquartile ranges) (non-normal distribution). HA + IGT, hyperandrogenemia combined with impaired glucose tolerance; HA + DM, hyperandrogenemia combined with diabetes mellitus; HA + NIR, hyperandrogenemia combined with non-insulin resistance; NHA + IR, non-hyperandrogenemia androgen combined with insulin resistance; NHA + NIR, non-hyperandrogenemia combined with non-insulin resistance; WHR, waist to hip ratio; BMI, body mass index; FSH, follicle-stimulating hormone; LH, luteinizing hormone; E2, estrogen; P, progesterone; PRL, prolactin; AMH, anti-mullerian hormone; TSH, thyroid-stimulating hormone; CHOL, cholesterol; TG, triglyceride; HDL, high-density lipoprotein; LDL, low-density lipoprotein; IU, international unit.

transformation, intravenous blood and endometrium samples were collected. To minimize the biopsy difference, the endometrial biopsies were collected from the superficial layer of the endometrium instead of the basal layer. The receptive phase of endometrium was determined according to Noyes histological standard (36).

High molecular weight (HMW) adiponectin ELISA detection. The sensitivity of specific ELISA kit (cat. no. ml063723, MiBio) of HMW adiponectin was $10 \mathrm{ng} / \mathrm{ml}$. The coefficient of variation within and between plates was $<10$ and $15 \%$, respectively. The serum HMW adiponectin was determined using enzyme-linked immunosorbent assay (ELISA) with an enzyme-labeled instrument (SkanIt ${ }^{\mathrm{TM}}$ software; Thermo Fisher Scientific, Inc.).

RNA extraction and PCR. The frozen endometrial samples were homogenized using TRIzol (cat. no.93289, Thermo Fisher Scientific, Inc.) reagent to obtain total ribonucleic acid (RNA). The RNA concentration was determined using spectrophotometry (A260:A280), and the integrity of RNA was determined using electrophoresis on a formaldehyde agarose gel. The tissue RNA extraction kit (EZBioscience) was used to extract $2 \mu \mathrm{g}$ of total RNA from the endometrial sample; the RNA reverse transcription and SYBR Green qPCR Master Mix kit (EZBioscience) were used to perform the standard PCR according to the manufacturer's instructions. Human GAPDH was used as internal reference genes and as a biomarker of standardizing to the RNA load of each sample since the expression of this gene is relatively constant during the menstrual cycle (37). PCR amplification of target mRNA was assessed by using gene-specific primers in Table II. Primers were provided by Takara Biotechnology Co., Ltd. The PCR reaction was initiated with $95^{\circ} \mathrm{C}$ for $5 \mathrm{~min}$ for amplification, melted at $95^{\circ} \mathrm{C}$ for $10 \mathrm{sec}$, then annealing and extension were performed at $60^{\circ} \mathrm{C}$ for $30 \mathrm{sec}$. The polymerase chain reaction products were analyzed using ethidium bromide agarose gel electrophoresis. A quantitative PCR instrument (Applied Biosystems; Thermo Fisher Scientific, Inc.) was used for real-time quantitative PCR and data analysis. Amplification efficiencies obtained from quantitative PCR were supported by using the method of $2^{-\Delta \Delta C q}$ (38).

The relative expression levels of all target genes were calculated by normalizing to the reference gene (GAPDH) $\left(2^{-\Delta \mathrm{Cq}}\right)$, and the relative expression of target genes in different groups was presented as the fold-change relative to the control groups $\left(2^{-\Delta \Delta \mathrm{Cq}}\right)$. For the comparison of different metabolic disorders, 
Table II. Gene-specific primer sequences.

\begin{tabular}{|c|c|}
\hline Target genes & Primer sequences $\left(5^{\prime}-3^{\prime}\right)$ \\
\hline GAPDH & $\begin{array}{l}\text { Sense GAGTCAACGGATTTGGTCGT } \\
\text { Antisense ATCCACAGTCTTCTGGGTG }\end{array}$ \\
\hline Adiponectin & $\begin{array}{l}\text { Sense TGCTGGGAGCTGTTCTACTG } \\
\text { Antisense TACTCCGGTTTCACCGATGTC }\end{array}$ \\
\hline AdipoR1 & $\begin{array}{l}\text { Sense AAACTGGCAACATCTGGACC } \\
\text { Antisense GCTGTGGGGAGCAGTAGAAG }\end{array}$ \\
\hline AdipoR2 & $\begin{array}{l}\text { Sense ACAGGCAACATTTGGACACA } \\
\text { Antisense CCAAGGAACAAAACTTCCCA }\end{array}$ \\
\hline APPL1 & $\begin{array}{l}\text { Sense TTAGCTGCCCGGGCCATCCATA } \\
\text { Antisense ATCTTTTCCCCCTCATTGTTTG }\end{array}$ \\
\hline MCP-1 & $\begin{array}{l}\text { Sense CAGCCAGATGCAATCAATGCC } \\
\text { Antisense TGGAATCCTGAACCCACTTCT }\end{array}$ \\
\hline IL-6 & $\begin{array}{l}\text { Sense CAGACAGCCACTCACCTCTTC } \\
\text { Antisense TGCCAGTGCCTCTTTGCT }\end{array}$ \\
\hline IL-8 & $\begin{array}{l}\text { Sense ATGACTTCCAAGCTGGCCGT } \\
\text { Antisense TCCTTGGCAAAACTGCACCT }\end{array}$ \\
\hline $\mathrm{ER} \alpha$ & $\begin{array}{l}\text { Sense GGTCAGTGCCTTGTTGGATG } \\
\text { Antisense TGCCAGGTTGGTCAGTAAGC }\end{array}$ \\
\hline $\mathrm{ER} \beta$ & $\begin{array}{l}\text { Sense ACTGGGATTGTGTGGTCAGC } \\
\text { Antisense AGAGGATAGGCATCGGCATT }\end{array}$ \\
\hline PR & $\begin{array}{l}\text { Sense TTTAAGAGGGCAATGGAAGG } \\
\text { Antisense CGGATTTTATCAACGATGCAG }\end{array}$ \\
\hline IL-15 & $\begin{array}{l}\text { Sense GTCCGGAGATGCAAGTATTCA } \\
\text { Antisense TCCTCACATTCTTTGCATCCA }\end{array}$ \\
\hline $\operatorname{av} \beta 3$ & $\begin{array}{l}\text { Sense AAGAGCCAGAGTGTCCCAAG } \\
\text { Antisense AGTTTCCAGATGAGCAGGGC }\end{array}$ \\
\hline IGFBP-1 & $\begin{array}{l}\text { Sense TTTTACCTGCCAAACTGCAACA } \\
\text { Antisense CCCATTCCAAGGGTAGACGC }\end{array}$ \\
\hline
\end{tabular}

GAPDH, Human glyceraldehyde-3-phosphate dehydrogenase; AdipoR, Adiponectin receptor; APPL1, adapter protein containing PH domain, PTB domain and leucine zipper motif 1; AdipoR, adiponectin receptor; MCP-1, monocyte chemoattractant protein-1; IL, interleukin; ER, estrogen receptor; PR, progesterone receptor; av $\beta 3$, integrin $\beta 3$; IGFBP-1, insulin-like growth factor binding protein-1.

the NHA + NIR group was used as the control group; for the comparison of different BMI values, the lean/normal group was selected as a control.

$u N K$ cell cycle analysis. On the fifth day of endometrial transformation, endometrium samples were collected using the Endometrial Sampler (TAO Brush ${ }^{\mathrm{TM}}$ IUMC). Endometrial tissue was weighed (weight, $300 \mu \mathrm{g}$ ) and immediately placed in PBS containing $0.25 \%$ collagenase from Clostridium histolyticum and $0.5 \%$ deoxyribonuclease bovine (all Sigma-Aldrich; Merck KGaA) All digestions were performed at $37^{\circ} \mathrm{C}$ for $20 \mathrm{~min}$ with agitation. The tissue was filtered with a filter (100 um) and was centrifuged at a speed of $350 \mathrm{~g}$ at $4^{\circ} \mathrm{C}$ for $5 \mathrm{~min}$. The supernatant was removed and the endometrial cells were placed in PBS. The uNK cells are characterized by CD3-/CD56 ${ }^{+}$
Table III. Comparisons of HMW adiponectin levels among groups.

\begin{tabular}{lcc}
\hline Groups & HMW adiponectin $(\mathrm{ng} / \mathrm{ml})$ & P-value \\
\hline HA + IGT & 4703.93 & \\
& $(4,148.54-4,768.53)$ & \\
HA + DM & $5,129.82 \pm 510.88$ & 0.11 \\
HA + NIR & $4,625.06 \pm 1,084.25$ & \\
NHA + IR & $4,626.95 \pm 452.29$ & \\
NHA + NIR & $4,283.51 \pm 407.41$ & \\
Lean/normal & $4,520.65 \pm 779.47$ & 0.53 \\
Overweight & $4,736.18 \pm 505.46$ & \\
Obese & $4,843.26 \pm 455.09$ & \\
\end{tabular}

Data are presented as means \pm SEM (normal distribution) or as medium (interquartile ranges) (non-normal distribution). HMW, High molecular weight; $\mathrm{P}$, probability.

granular lymphocytes, while the expression of CD16 is relatively low compared with peripheral blood natural killer cells (39). Cells were stained with the following monoclonal antibodies conjugated with FITC PE and APC at $20^{\circ} \mathrm{C}$ for $20 \mathrm{~min}$ : CD3 (FITC anti-human; cat. no. 300402 UCHT1, BioLegend), CD16 (PE anti-human cat. no. 302003 3G8, BioLegend), CD56 (APC anti-human; cat. no. 362535 NCAM, BioLegend). Cells were acquired within $24 \mathrm{~h}$ of staining on a BD FACSAria flow cytometer (BD Biosciences). A gate set around CD3-lymphocytes was used to measure the proportion of NK-cell subsets within each sample. In the case of the NK-cell subset, a gate set around CD56+ lymphocytes was used to exclude NK-T-cell subset (Figs. S1 and S2). CELLQuest software (version 5.1 Becton Dickinson) was used for the data analysis.

Statistical analysis. In order to obtain statistical significance results, the number of subjects were calculated: $n=2 x[(t \alpha+t \beta)$ $\sigma / \delta]^{2}(40)$, the test level $\alpha$ was set to 0.05 and the inspection power $1-\beta$ was set to $90 \%$, checked the t boundary value table and only take one-sided, $\mathrm{t}(\alpha=0.05)=1.645$, one-sided $\mathrm{t}(\beta=0.1)=1.282$. By consulting the literature (41), the discrimination $(\delta)$ and the standard deviation $(\sigma)$ were substituted into the formula, samples required for each group was 8 . SPSS software (version 20.0; IBM Corp.) was used for the statistical analysis. Normally distributed data were presented as mean \pm standard deviation (SD), and the comparison between groups was performed using one-way analysis of variance. The data that was not normally distributed was presented as the median and interquartile range, and the comparison between groups was performed using the Kruskal-Wallis test. The Bonferroni test was used to analyze the post-hoc paired comparison. $\mathrm{P}<0.05$ was considered to indicate a statistically significant difference.

\section{Results}

Demographic data. As presented in Table I, there was no statistical difference in other clinical and endocrine characteristics among HA + IGT, HA + DM, HA + NIR, NHA + IR and 
NHA + NIR groups $(\mathrm{P}>0.05)$. However, only the comparison of BMI between the HA + IGT group $\left(27.45 \mathrm{~kg} / \mathrm{m}^{2}\right)$ and the NHA + NIR group $\left(19.11 \mathrm{~kg} / \mathrm{m}^{2}\right)$ demonstrated a significant difference $(\mathrm{P}<0.05)$.

$H M W$ adiponectin. There was no significant difference in serum HMW adiponectin in patients across HA + IGT, $\mathrm{HA}+\mathrm{DM}, \mathrm{HA}+\mathrm{NIR}, \mathrm{NHA}+\mathrm{IR}$ and NHA + NIR groups $(\mathrm{P}>0.05)$. In addition, no significant difference was revealed in serum HMW adiponectin in patients in lean/normal, overweight, and obese groups $(\mathrm{P}>0.05$; Table III).

Endometrial receptivity-related factors. The relative mRNA expression levels of adiponectin, AdipoR1, AdipoR2, APPL1, $\mathrm{ER} \alpha, \mathrm{ER} \beta, \mathrm{PR}, \mathrm{IL}-15$, av $\beta 3$ and IGFBP-1 were significantly decreased, while the expression levels of IL-6 and IL-8 were significantly increased in HA + IGT, HA + DM, HA + NIR and NHA + IR groups when compared with the NHA + NIR group (all $\mathrm{P}<0.05$ ). However, no significant difference was revealed amongst the HA + DM, HA + NIR, and NHA + IR groups (Fig. 1).

For the comparison of different bodyweight groups, the relative mRNA expression levels of adiponectin, AdipoR1, AdipoR2, APPL1, ER $\alpha$, ER $\beta$, PR, IL-15, av $\beta 3$, and IGFBP-1 were significantly lower, while the expression of MCP-1, IL-6 and IL-8 were significantly higher in the overweight and obese groups when compared with the lean/normal group (all $\mathrm{P}<0.05$ ). Furthermore, the relative mRNA expression of $\mathrm{PR}$ in the obese group was significantly higher compared with that in the overweight group $(\mathrm{P}<0.01$; Fig. 1$)$.

Proportion of uNK cells. As presented in Fig. 2, the percentages of $\mathrm{CD} 16 \% \mathrm{CD}^{2} 6^{+}$and $\mathrm{CD} 16^{+} / \mathrm{CD} 56^{+}$in endometrium were comparable across HA + IGT, HA + DM, HA + NIR, $\mathrm{NHA}+\mathrm{IR}$ and NHA + NIR groups $(\mathrm{P}>0.05)$. In addition, no significant difference was revealed among patients in the lean/normal, overweight and obese groups $(\mathrm{P}>0.05)$.

\section{Discussion}

Wickham et al (42) hypothesized that IR can reduce serum HMW adiponectin, while O'Connor et al (43) claimed that serum HMW adiponectin is not dependent on IR. On the other hand, studies have indicated that high androgen status may indirectly reduce serum HMW adiponectin in patients with PCOS $(44,45)$, but the evidence was still insufficient. Garcia et al (41) revealed that the serum adiponectin level in obese patients with PCOS was lower compared with that in the lean or obese patient groups. Nevertheless, other studies revealed no differences in the expression of adiponectin (46) or HMW adiponectin (47) among overweight/obese or normal-weight patients between PCOS and control groups. So far, there is no consensus on whether there are differences in serum adiponectin in different types of patients with PCOS (42-47). The present study revealed no significant difference in serum HMW adiponectin levels among different high androgen statuses, insulin-resistant levels or BMI levels in patients with PCOS. The various patient group settings and the detection method used for HMW adiponectin may explain the inconsistency in results compared with previous studies.
Although the present study revealed no differences in HMW adiponectin, this does not mean that there was no difference in other forms of adiponectin. The alteration in other molecular forms of adiponectin should also be considered, and this needs further exploration.

The endometrium undergoes three different phases during the normal menstrual cycle, which is induced by the steroid hormones fluctuation (48). Estrogen (E2) promotes the expression of estrogen receptor $\alpha(\operatorname{Er} \alpha)$ and estrogen receptor $\beta(\operatorname{Er} \beta)$; the expression levels of these receptors are highest in the late stage of proliferation. In addition, E2, together with ER, promotes progesterone receptor (PR) expression in the endometrium. After ovulation, progesterone inhibits the expression of ER in the endometrium, thus inducing decidualization. Decidualization is a necessary transformation of endometrium for successful embryo implantation, including endometrial stromal cells proliferation, the increase of glandular epithelial secretion and natural killer cells aggregation (24). Decidualization usually happens at 5-6 days after ovulation (49). The process of decidualization is accompanied by the alteration of ER, PR and inhibition of pro-inflammatory cytokines (interleukin and MCP-1) and endometrial pathological and physiological-related factors (av $\beta 3$, IGFBP-1) $(24,50)$. Some researchers hypothesize that the decreased expression of ER $\alpha, E R \beta, P R$, IL-15, av $\beta 3$ and IGFBP-1 may indicate the decline of embryo implantation rate (51-54); however, the mechanism of how these factors affect endometrial receptivity remains unclear. Furthermore, previous studies have revealed increased expression of Era $(37,55,56)$ and PR (56), decreased expression of IL-15 (39), avß3 (57) and IGFBP-1 (58) and unchanged expression of $\operatorname{Er} \beta$ (58) in secretory phase endometrium in patients with PCOS when compared with non-PCOS patients.

The present study demonstrated that the expression levels of ER $\alpha, E R \beta, P R, I L-15$, av $\beta 3$ and IGFBP-1 were significantly decreased in the presence of HA and/or IR and/or obesity (BMI $\geq 24 \mathrm{~kg} / \mathrm{m}^{2}$ ), which were consistent with previous studies by Matteo et al (39), Cermik et al (57) and Piltonen et al (58). Nevertheless, the results were different from the findings by Margarit et al (56) and Quezada et al (37). The difference may be due to the diversity in studied population. Apart from the distinction of the hyperandrogenemia states, the IR levels and BMI, the control group used in previous studies were different. All previous studies were carried out with in untreated patients with PCOS (with spontaneous ovulation) and non-PCOS patients. By contrast, patients in the present study were treated with HRT to guarantee the endometrial transformation.

During the menstrual cycle, adiponectin and its receptors can be detected, the mRNA expression of adiponectin increased significantly in the early stage of proliferation; however, the mRNA expression levels of AdipoR1 and AdipoR2 increased significantly in the peri-implantation period (25). These changes have been confirmed in the artificial decidua model as well (59). Adiponectin has been indicated to be reduced in the endometrium of obese and PCOS patients (60). Garcia et al (41) demonstrated that the obese group (compared with the lean group) have an increased expression of endometrial AdipoR1 and a decreased expression of endometrial APPL1, while the AdipoR2 expression is similar (41). In addition, they demonstrated that when treating immortalized human endometrial stromal cell lines with testosterone and 


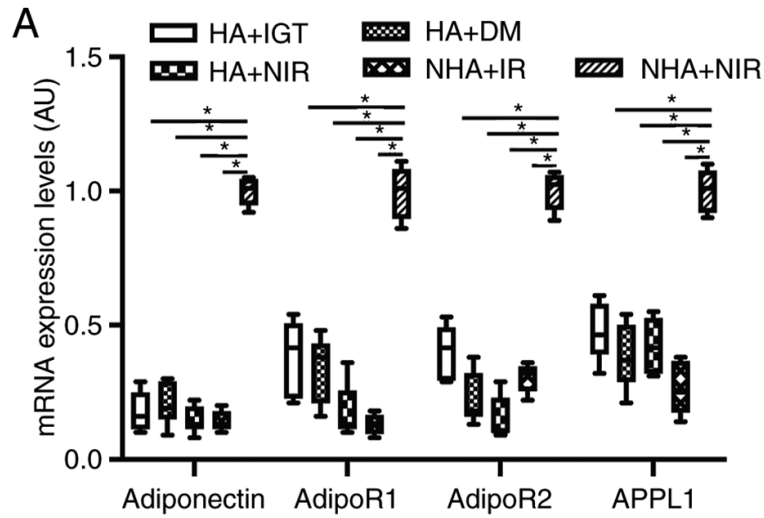

$\mathrm{B}$
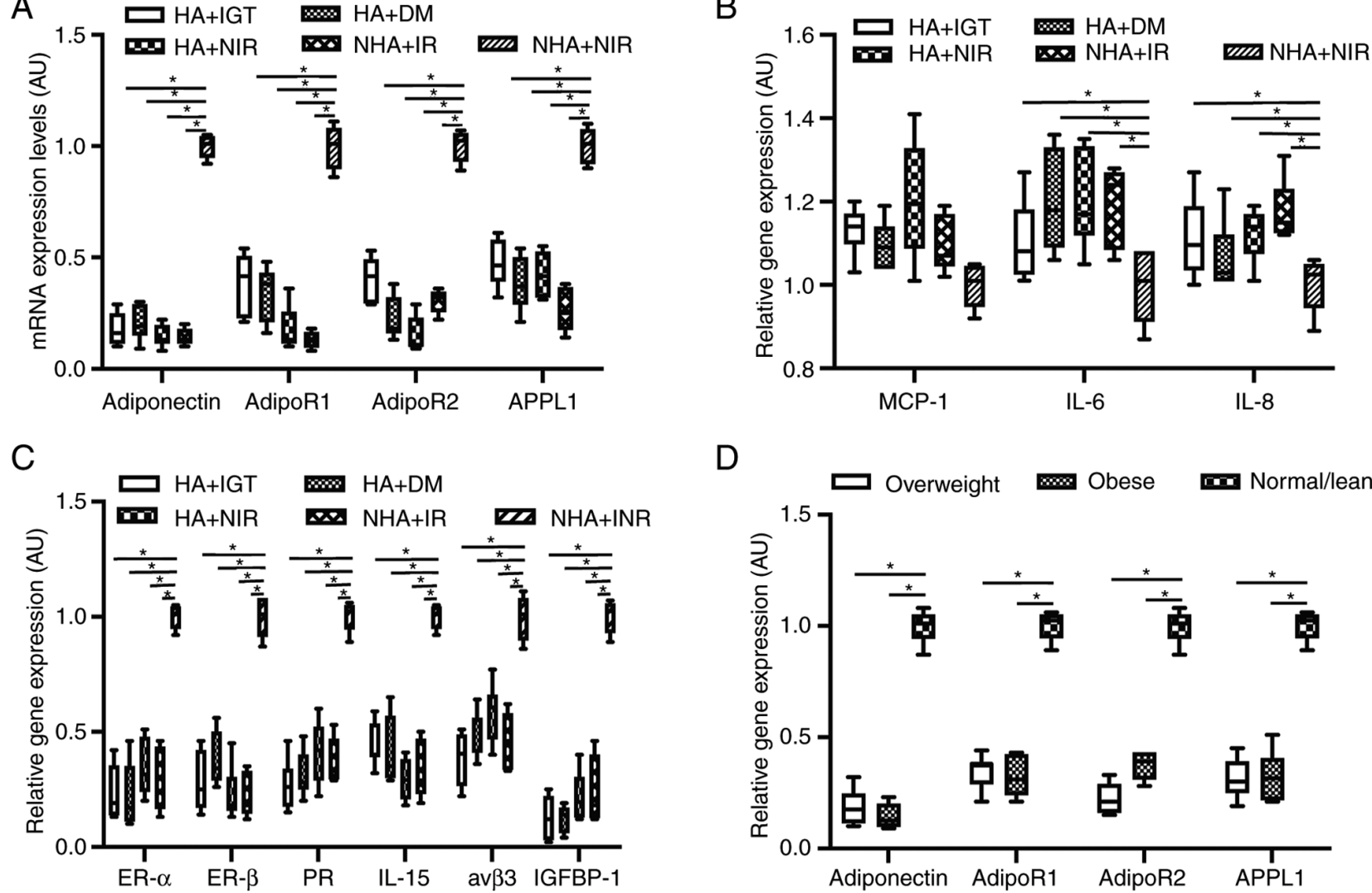

$\mathrm{D}$

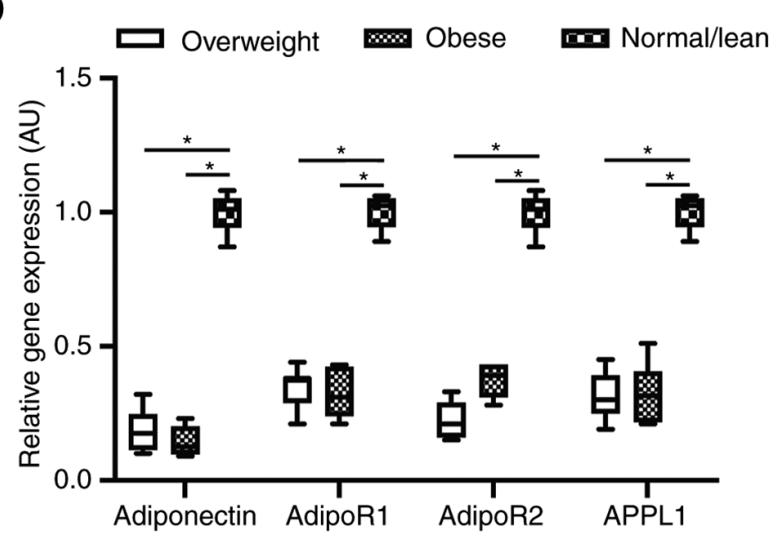

E

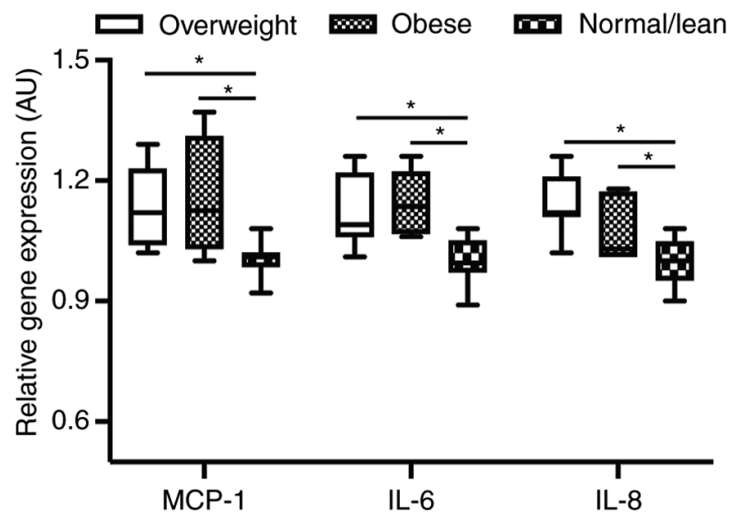

F

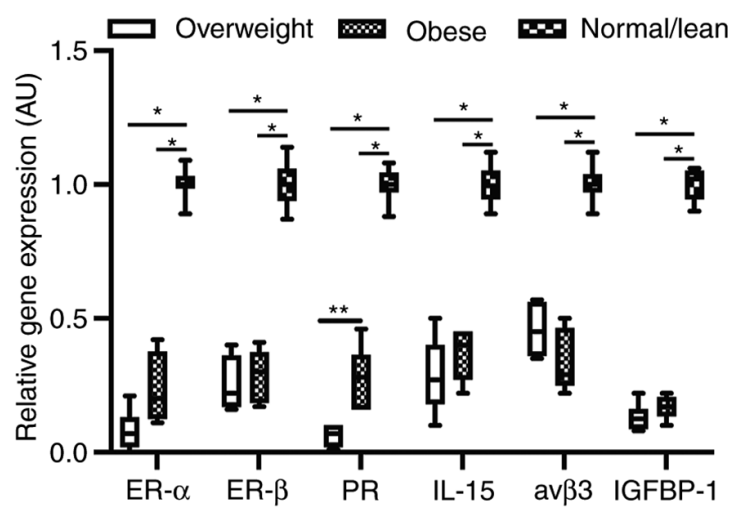

Figure 1. Relative mRNA levels of receptivity-related factors in the endometrium across studied groups. Relative mRNA levels of (A) adiponectin, AdipoR1, AdipoR2 and APPL1, (B) MCP-1, IL-6 and IL-8 and (C) ER $\alpha$, ER $\beta$, PR, IL-15, av $\beta 3$ and IGFBP-1 of receptivity-related factors in endometrium obtained from $\mathrm{HA}+\mathrm{IGT}, \mathrm{HA}+\mathrm{DM}, \mathrm{HA}+\mathrm{NIR}$ and NHA + IR groups. For each gene, the mRNA expression levels were normalized to the mean value of NHA + NIR group (internal control). Relative mRNA levels of (D) adiponectin, AdipoR1, AdipoR2 and APPL1, (E) MCP-1, IL-6 and IL-8 and (F) ER $\alpha$, ER $\beta$, PR, IL-15, av $\beta 3$ and IGFBP-1 of receptivity-related factors in endometrium obtained from lean/normal, overweight and obese groups. For each gene, the mRNA expression levels were normalized to the mean value of lean/normal group (internal control). ${ }^{*} \mathrm{P}<0.05,{ }^{* *} \mathrm{P}<0.01$. HA, hyperandrogenemia; IGT, impaired glucose tolerance; DM, diabetes mellitus; NIR, non-insulin resistance; NHA, non-hyperandrogenemia androgen; IR, insulin resistance; AdipoR, adiponectin receptor; APPL1, adapter protein containing PH domain, PTB domain and leucine zipper motif 1; MCP-1, monocyte chemoattractant protein-1; IL, interleukin; ER, estrogen receptor; PR, progesterone receptor; av $\beta 3$, integrin $\beta 3$; IGFBP-1, insulin-like growth factor binding protein-1.

insulin, the mRNA expression levels of adiponectin, AdipoR1, AdipoR2 and APPL1 are significantly decreased (41).

Similarly, partly consistent with previous studies $(37,41)$, the present study revealed that the mRNA expression levels of adiponectin, AdipoR1, AdipoR2 and APPL1 were significantly decreased in the presence of HA and/or IR and/or obesity $\left(\mathrm{BMI} \geq 24 \mathrm{~kg} / \mathrm{m}^{2}\right.$ ) when compared with the $\mathrm{NHA}+\mathrm{NIR}$ group and the lean/normal group, respectively. These findings were different from the results of Garcia et al (41), and this may be explained by the variance in sample collection. Garcia et al (41) collected samples in the proliferative phase and set untreated patients with PCOS (with spontaneous ovulation) as the control group. By contrast, all the patients with PCOS in the present study were treated with HRT, and endometrium samples were collected during the window of implantation in the HRT cycle.

MCP-1, IL-6 and IL-8 are pro-inflammatory factors which are involved in the morphological and pathological changes 
A

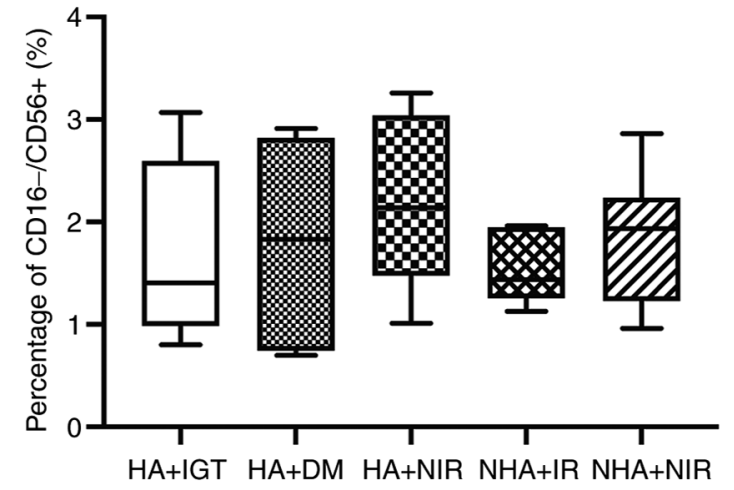

C

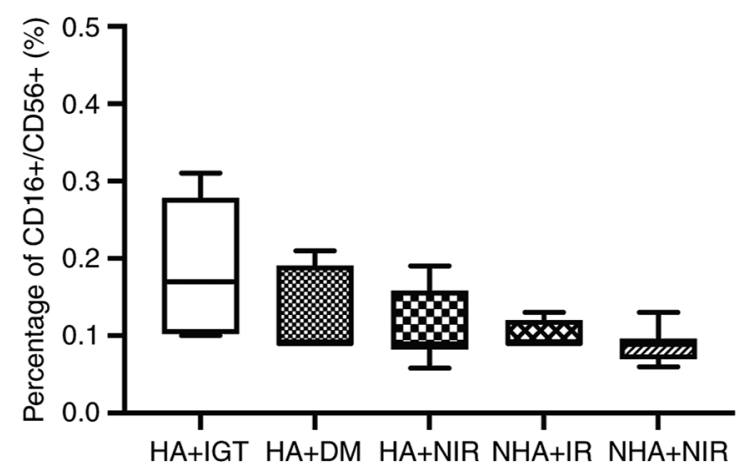

B

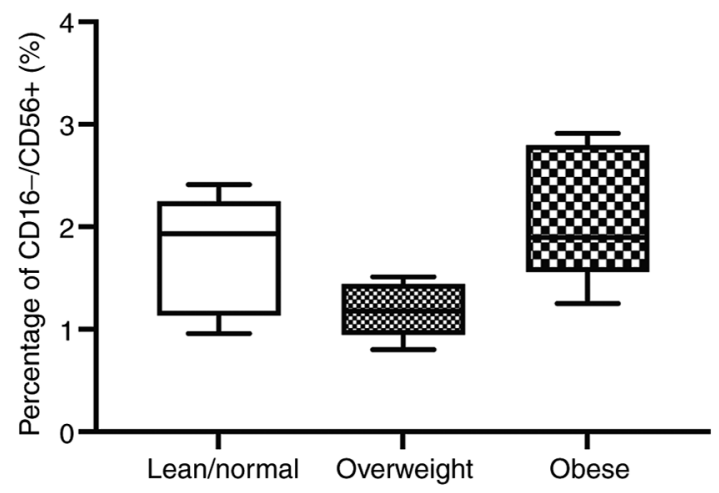

D

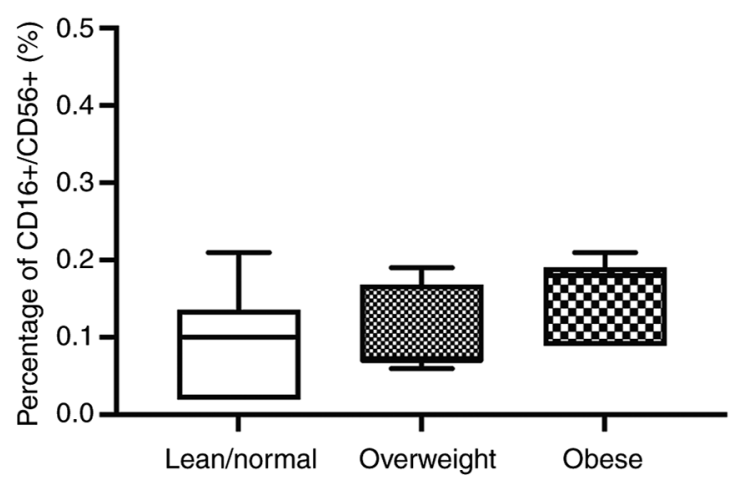

Figure 2. Percentage of subgroups of uNK cells in the endometrium across studied groups. Percentage of CD16-/CD56+ in endometrium obtained from (A) HA + IGT, HA + DM, HA + NIR and NHA + IR groups and (B) from lean/normal, overweight, and obese groups. (C) Percentage of CD16+/CD56+ in endometrium obtained from (C) HA + IGT, HA + DM, HA + NIR and NHA + IR groups and (D) from lean/normal, overweight and obese groups. HA, hyperandrogenemia; IGT, impaired glucose tolerance; DM, diabetes mellitus; NIR, non-insulin resistance; NHA, non-hyperandrogenemia androgen; IR, insulin resistance; uNK cells, uterine natural killer cells.

in the process of endometrial decidualization (61). It has been demonstrated that adiponectin exerts anti-inflammatory effects in the endometrium by inhibiting the production of pro-inflammatory cytokines (IL-6, IL-8 and MCP-1) (5). Compared with the NHA + NIR group and the lean/normal group, the expression levels of MCP-1, IL-6 and IL-8 were significantly increased in the endometrium in the presence of $\mathrm{HA}$ and/or IR and/or obesity $\left(\mathrm{BMI} \geq 24 \mathrm{~kg} / \mathrm{m}^{2}\right)$ of patients with PCOS. It was hypothesized that the reduction of adiponectin may explain the increased levels of IL-6, IL-8 and MCP-1 in the endometrium.

Rosenbaum et al (30) revealed that obesity can affect endometrial decidualization in the mouse model and human embryonic stem cells. In addition, Comstock et al (62) claimed that obesity can change the expression of genes involved in implantation-related chemokine signaling pathways during implantation, especially in obese patients with metabolic syndrome (63). Notably, the present study revealed that the mRNA expression level of PR in the obese group was significantly higher compared with that in the overweight group. We hypothesized that obesity increased the expression of PR as the response to progesterone resistance (53). However, the underlying mechanism remains elusive and further studies are needed.

As a factor associated with endometrial receptivity $(39,64)$, the percentage of uNK cells fluctuates along with the hormones changing during the menstrual cycle $(65,66)$, which increases during the secretory phase (39). However, increases in the number of peripheral blood and endometrial NK cells $\left(\mathrm{CD}^{+} 6^{+}\right)$have been used as an indicator to assess the risk of infertility or recurrent miscarriage (39). Piltonen et al (67) and Matteo et al (39) revealed that uNK cells decrease in the late menstrual secretion period, and the percentage of uNK cells $\mathrm{CD}^{+} 6^{+} / \mathrm{CD} 56^{+}$is similar, while the percentage of $\mathrm{CD} 16^{-} / \mathrm{CD}^{2} 6^{+}$ is lower in the secretion phase in patients with PCOS when compared with the control group. Nevertheless, no significant difference was revealed in the present study in uNK cells among patients with PCOS with different BMI, androgen status and IR levels. Considering the different phases of the menstrual cycle, the percentage of $\mathrm{CD} 16^{\%} / \mathrm{CD} 56^{+}$was observed to decrease after implantation, while a previous study revealed the percentage of $\mathrm{CD} 16 / \mathrm{CD} 56^{+}$was lower in the late menstrual secretion period (67). But this research needs to be explored further.

To avoid the impact of actual human embryo implantation on the endometrium, the present investigation was not performed in a conception cycle but in the HRT cycles. The HRT treatment was performed in all the patients with PCOS to promote endometrial transformation and cause implantation window-related changes. Although a previous study indicated that ER and PR expression is significantly decreased in the endometrium in the early luteal phase of HRT cycles (68), all the studied patients in the present study were treated with HRT; therefore avoiding the impact of internal hormone alteration caused by ovulation, and ensuring all patients were 
in the same endometrial phase. In the majority of previous studies $(24,37,41)$ the expression of receptivity markers are measured from mRNA level. However, to clarify the differences in the expression level of theses markers, the detection from protein level is important; thus further exploration is needed to validate the present findings.

In conclusion, evidence regarding secretory endometrial receptivity factors in patients with PCOS is limited, so consistent conclusions cannot yet be made. The present study revealed that the IR status, hyperandrogenemia and obesity would impact the endometrial receptivity in patients with PCOS, which may explain the damaged embryo implantation and pregnancy outcomes. To develop the targeted therapies and improve pregnancy outcomes in patients with PCOS, further studies are needed to investigate the underlying mechanism of the impaired endometrium receptivity caused by metabolic disorders.

\section{Acknowledgements}

Not applicable.

\section{Funding}

No funding was received.

\section{Availability of data and materials}

The datasets used and/or analyzed during the current study are available from the corresponding author on reasonable request.

\section{Authors' contributions}

CW and QYM conceptualized the study and analyzed and interpreted the data. CW and YXW performed experiments and wrote the manuscript. CW and QYM confirm the authenticity of all the raw data. All authors have read and approved the final manuscript.

\section{Ethics approval and consent to participate}

The present study was approved by the Clinical Scientific Research and Experimental Animal Ethics Committee of the First Affiliated Hospital of Sun Yat-sen University [approval no. Ethics (2020) no. 422-1]. Written informed consent was obtained from all participants.

\section{Patient consent for publication}

Not applicable.

\section{Competing interests}

The authors declare that they have no competing interests.

\section{References}

1. Dabadghao P, Roberts BJ, Wang J, Davies MJ and Norman RJ Glucose tolerance abnormalities in Australian women with polycystic ovary syndrome. Med J Aust 187: 328-331, 2007.
2. Li R, Zhang Q, Yang D, Li S, Lu S, Wu X, Wei Z, Song X, Wang X, Fu S, et al: Prevalence of polycystic ovary syndrome in women in China: A large community-based study. Hum Reprod 28: 2562-9256, 2013.

3. Ovalle F and Azziz R: Insulin resistance, polycystic ovary syndrome, and type 2 diabetes mellitus. Fertil Steril 77: 1095-1105, 2002.

4. DeUgarte CM, Bartolucci AA and Azziz R: Prevalence of insulin resistance in the polycystic ovary syndrome using the homeostasis model assessment. Fertil Steril 83: 1454-1460, 2005.

5. Carmina E and Lobo RA: Use of fasting blood to assess the prevalence of insulin resistance in women with polycystic ovary syndrome. Fertil Steril 82: 661-665, 2004.

6. Moran LJ, Pasquali R, Teede HJ, Hoeger KM and Norman RJ: Treatment of obesity in polycystic ovary syndrome: A position statement of the androgen excess and polycystic ovary syndrome society. Fertil Steril 92: 1966-1982, 2009.

7. Greenwood EA and Huddleston HG: Insulin resistance in polycystic ovary syndrome: Concept versus cutoff. Fertil Steril 112: 827-828, 2019.

8. Zeng X, Xie YJ, Liu YT, Long SL and Mo ZC: Polycystic ovarian syndrome: Correlation between hyperandrogenism, insulin resistance and obesity. Clin Chim Acta 502: 214-221, 2020.

9. Xiao XU and Xue-Lian LI: The role of androgens in the pathogenesis and treatment of female reproductive endocrine diseases. J Int Obstet Gynecol 46: 229-232, 2019.

10. Patlolla S, Vaikkakara S, Sachan A, Venkatanarasu A, Bachimanchi B, Bitla A, Settipalli S, Pathiputturu S, Sugali RN and Chiri S: Heterogenous origins of hyperandrogenism in the polycystic ovary syndrome in relation to body mass index and insulin resistance. Gynecol Endocrinol 34: 238-242, 2018.

11. Naver KV, Grinsted J, Larsen SO, Hedley PL, Jørgensen FS, Christiansen $\mathrm{M}$ and Nilas L: Increased risk of preterm delivery and pre-eclampsia in women with polycystic ovary syndrome and hyperandrogenaemia. BJOG 121: 575-581, 2014.

12. Elenis E, Desroziers E, Persson S, Sundström Poromaa I and Campbell RE: Early initiation of anti-androgen treatment is associated with increased probability of spontaneous conception leading to childbirth in women with polycystic ovary syndrome: A population-based multiregistry cohort study in Sweden. Hum Reprod 36: 1427-1435, 2021.

13. Chang EM, Han JE, Seok HH, Lee DR, Yoon TK and Lee WS: Insulin resistance does not affect early embryo development but lowers implantation rate in in vitro maturation-in vitro fertilization-embryo transfer cycle. Clin Endocrinol 79: 93-99, 2013.

14. Tian L, Shen H, Lu Q, Norman RJ and Wang J: Insulin resistance increases the risk of spontaneous abortion after assisted reproduction technology treatment. J Clin Endocrinol Metab 92: 1430-1433, 2007.

15. Khattab S, Mohsen IA, Foutouh IA, Ramadan A, Moaz M and Al-Inany $\mathrm{H}$ : Metformin reduces abortion in pregnant women with polycystic ovary syndrome. Gynecol Endocrinol 22: 680-684, 2006.

16. Huang K, Liao $X$, Dong $X$ and Zhang $H$ : Effect of overweight/obesity on IVF-ET outcomes in Chinese patients with polycystic ovary syndrome. Int J Clin Exp Med 7: 5872-5876, 2014.

17. Veleva Z, Tiitinen A, Vilska S, Hydén-Granskog C, Tomás C, Martikainen $\mathrm{H}$ and Tapanainen JS: High and low BMI increase the risk of miscarriage after IVF/ICSI and FET. Hum Reprod 23: 878-884, 2008.

18. Fedorcsák P, Storeng R, Dale PO, Tanbo T and Abyholm T: Obesity is a risk factor for early pregnancy loss after IVF or ICSI. Acta Obstet Gynecol Scand 79: 43-48, 2000.

19. Bu Z, Dai W, Guo Y, Su Y, Zhai J and Sun Y: Overweight and obesity adversely affect outcomes of assisted reproductive technologies in polycystic ovary syndrome patients. Int J Clin Exp Med 6: 991-995, 2013.

20. Patel SS and Carr BR: Oocyte quality in adult polycystic ovary syndrome. Semin Reprod Med 26: 196-203, 2008.

21. Jungheim ES, Schon SB, Schulte MB, DeUgarte DA, Fowler SA and Tuuli MG: IVF outcomes in obese donor oocyte recipients: A systematic review and meta-analysis. Hum Reprod 28: 2720-2727, 2013.

22. Wattanakumtornkul S, Damario MA, Stevens HS, Thornhill AR and Tummon IS: Body mass index and uterine receptivity in the oocyte donation model. Fertil Steril 80: 336-340, 2003. 
23. Bellver J, Rossal LP, Bosch E, Zúñiga A, Corona JT, Meléndez F, Gómez E, Simón C, Remohí J and Pellicer A: Obesity and the risk of spontaneous abortion after oocyte donation. Fertil Steril 79: 1136-1140, 2003.

24. Piltonen TT: Polycystic ovary syndrome: Endometrial markers. Best Pract Res Clin Obstet Gynaecol 37: 66-79, 2016.

25. Takemura Y, Osuga Y, Yamauchi T, Kobayashi M, Harada M, Hirata T, Morimoto C, Hirota Y, Yoshino O, Koga K, et al: Expression of adiponectin receptors and its possible implication in the human endometrium. Endocrinology 147: 3203-3210, 2006.

26. Wang $Y, X i e ~ X$ and $Z$ hu W: Serum adiponectin and resistin levels in patients with polycystic ovarian syndrome and their clinical implications. J Huazhong Univ Sci Technolog Med Sci 30: 638-642, 2010

27. Barbe A, Bongrani A, Mellouk N, Estienne A, Kurowska P, Grandhaye J, Elfassy Y, Levy R, Rak A, Froment P and Dupont J: Mechanisms of adiponectin action in fertility: An overview from gametogenesis to gestation in humans and animal models in normal and pathological conditions. Int J Mol Sci 20: 1526, 2019.

28. Fisher FM, Trujillo ME, Hanif W, Barnett AH, McTernan PG, Scherer PE and Kumar S: Serum high molecular weight complex of adiponectin correlates better with glucose tolerance than total serum adiponectin in Indo-Asian males. Diabetologia 48: 1084-1087, 2005.

29. Yamauchi T, Iwabu M, Okada-Iwabu M and Kadowaki T: Adiponectin receptors: A review of their structure, function and how they work. Best Pract Res Clin Endocrinol Metab 28: 15-23, 2014.

30. Rosenbaum D, Haber RS and Dunaif A: Insulin resistance in polycystic ovary syndrome: Decreased expression of GLUT-4 glucose transporters in adipocytes. Am J Physiol 264: E197-E202, 1993.

31. Rotterdam ESHRE/ASRM-Sponsored PCOS Consensus Workshop Group: Revised 2003 consensus on diagnostic criteria and long-term health risks related to polycystic ovary syndrome. Fertil Steril 81: 19-25, 2004.

32. Chang WY, Knochenhauer ES, Bartolucci AA and Azziz R Phenotypic spectrum of polycystic ovary syndrome: Clinical and biochemical characterization of the three major clinical subgroups. Fertil Steril 83: 1717-1723, 2005.

33. Soonthornpun S, Setasuban W, Thamprasit A, Chayanunnukul W, Rattarasarn C and Geater A: Novel insulin sensitivity index derived from oral glucose tolerance test. J Clin Endocrinol Metab 88: 1019-1023, 2003.

34. Salley KE, Wickham EP, Cheang KI, Essah PA, Karjane NW and Nestler JE: Glucose intolerance in polycystic ovary syndrome-a position statement of the androgen excess society. J Clin Endocrinol Metab 92: 4546-4556, 2007.

35. Finucane MM, Stevens GA, Cowan MJ, Danaei G, Lin JK, Paciorek CJ, Singh GM, Gutierrez HR, Lu Y, Bahalim AN, et al: National, regional, and global trends in body-mass index since 1980: Systematic analysis of health examination surveys and epidemiological studies with 960 country-years and 9.1 million participants. Lancet 377: 557-567, 2011.

36. Noyes RW, Hertig AT and Rock J: Reprint of: Dating the endometrial biopsy. Fertil Steril 112 (4 Suppl 1): e93-e115, 2019.

37. Quezada S, Avellaira C, Johnson MC, Gabler F, Fuentes A and Vega M: Evaluation of steroid receptors, coregulators, and molecules associated with uterine receptivity in secretory endometria from untreated women with polycystic ovary syndrome. Fertil Steril 85: 1017-1026, 2006.

38. Livak KJ and Schmittgen TDL: Analysis of relative gene expression data using real-time quantitative PCR and the 2(-Delta Delta C(T)) method. Methods 25: 402-408, 2001.

39. Matteo M, Serviddio G, Massenzio F, Scillitani G, Castellana L, Picca G, Sanguedolce F, Cignarelli M, Altomare E, Bufo P, et al: Reduced percentage of natural killer cells associated with impaired cytokine network in the secretory endometrium of infertile women with polycystic ovary syndrome. Fertil Steril 94 : 2222-2227, 2227.e1-e3, 2010.

40. Sinclair JC and Haynes RB: Selecting participants that raise a clinical trial's population attributable fraction can increase the treatment effect within the trial and reduce the required sample size. J Clin Epidemiol 64: 893-902, 2011.

41. Garcia V, Oróstica L, Poblete C, Rosas C, Astorga I, Romero C and Vega M: Endometria from obese PCOS women with hyperinsulinemia exhibit altered adiponectin signaling. Horm Metab Res 47: 901-909, 2015.
42. Wickham ER III, Cheang KI, Clore JN, Baillargeon JP and Nestler JE: Total and high-molecular weight adiponectin in women with the polycystic ovary syndrome. Metabolism 60: 366-372, 2011

43. O'Connor A, Phelan N, Tun TK, Boran G, Gibney J and Roche HM: High-molecular-weight adiponectin is selectively reduced in women with polycystic ovary syndrome independent of body mass index and severity of insulin resistance. J Clin Endocrinol Metab 95: 1378-1385, 2010.

44. Panidis D, Kourtis A, Farmakiotis D, Mouslech T, Rousso D and Koliakos G: Serum adiponectin levels in women with polycystic ovary syndrome. Hum Reprod 18: 1790-1796, 2003.

45. Xu A, Chan KW, Hoo RL, Wang Y, Tan KC, Zhang J, Chen B, Lam MC, Tse C, Cooper GJ and Lam KS: Testosterone selectively reduces the high molecular weight form of adiponectin by inhibiting its secretion from adipocytes. J Biol Chem 280: 18073-18080, 2005.

46. Lecke SB, Mattei F, Morsch DM and Spritzer PM: Abdominal subcutaneous fat gene expression and circulating levels of leptin and adiponectin in polycystic ovary syndrome. Fertil Steril 95: 2044-2049, 2011.

47. Barber TM, Hazell M, Christodoulides C, Golding SJ, Alvey C, Burling K, Vidal-Puig A, Groome NP, Wass JA, Franks S and McCarthy MI: Serum levels of retinol-binding protein 4 and adiponectin in women with polycystic ovary syndrome: Associations with visceral fat but no evidence for fat mass-independent effects on pathogenesis in this condition. J Clin Endocrinol Metab 93: 2859-2865, 2008

48. Snijders MP, de Goeij AF, Debets-Te Baerts MJ, Rousch MJ, Koudstaal J and Bosman FT: Immunocytochemical analysis of oestrogen receptors and progesterone receptors in the human uterus throughout the menstrual cycle and after the menopause. J Reprod Fertil 94: 363-371, 1992.

49. Gellersen B and Brosens JJ: Cyclic decidualization of the human endometrium in reproductive health and failure. Endocr Rev 35: 851-905, 2014

50. Weyer C, Tataranni PA, Bogardus C and Pratley RE: Insulin resistance and insulin secretory dysfunction are independent predictors of worsening of glucose tolerance during each stage of type 2 diabetes development. Diabetes Care 24: 89-94, 2001.

51. Benkhalifa M, Madkour A, Louanjli N, Bouamoud N, Saadani B, Kaarouch I, Chahine H, Sefrioui O, Merviel P and Copin H: From global proteome profiling to single targeted molecules of follicular fluid and oocyte: Contribution to embryo development and IVF outcome. Expert Rev Proteomics 12: 407-423, 2015.

52. Lessey BA, Palomino WA, Apparao KB, Young SL and Lininger RA: Estrogen receptor-alpha (ER-alpha) and defects in uterine receptivity in women. Reprod Biol Endocrinol 4 (Suppl 1): S9, 2006.

53. Young SL and Lessey BA: Progesterone function in human endometrium: Clinical perspectives. Semin Reprod Med 28: $5-16,2010$.

54. Gnainsky Y, Granot I, Aldo PB, Barash A, Or Y, Schechtman E, Mor G and Dekel N: Local injury of the endometrium induces an inflammatory response that promotes successful implantation. Fertil Steril 94: 2030-2036, 2010.

55. Gregory CW, Wilson EM, Apparao KB, Lininger RA, Meyer WR, Kowalik A, Fritz MA and Lessey BA: Steroid receptor coactivator expression throughout the menstrual cycle in normal and abnormal endometrium. J Clin Endocrinol Metab 87: 2960-2966, 2002.

56. Margarit L, Taylor A, Roberts MH, Hopkins L, Davies C, Brenton AG, Conlan RS, Bunkheila A, Joels L, White JO and Gonzalez D: MUC1 as a discriminator between endometrium from fertile and infertile patients with PCOS and endometriosis. J Clin Endocrinol Metab 95: 5320-5329, 2010.

57. Cermik D, Selam B and Taylor HS: Regulation of HOXA-10 expression by testosterone in vitro and in the endometrium of patients with polycystic ovary syndrome. J Clin Endocrinol Metab 88: 238-243, 2003.

58. Piltonen TT, Chen JC, Khatun M, Kangasniemi M, Liakka A, Spitzer T, Tran N, Huddleston H, Irwin JC and Giudice LC: Endometrial stromal fibroblasts from women with polycystic ovary syndrome have impaired progesterone-mediated decidualization, aberrant cytokine profiles and promote enhanced immune cell migration in vitro. Hum Reprod 30: 1203-1215, 2015.

59. Gamundi-Segura S, Serna J, Oehninger S, Horcajadas JA and Arbones-Mainar JM: Effects of adipocyte-secreted factors on decidualized endometrial cells: Modulation of endometrial receptivity in vitro. J Physiol Biochem 71: 537-546, 2015. 
60. Palin MF, Bordignon VV and Murphy BD: Adiponectin and the control of female reproductive functions. Vitam Horm 90: 239-287, 2012

61. Yoshino O, Osuga Y, Hirota Y, Koga K, Hirata T, Yano T, Ayabe T, Tsutsumi O and Taketani Y: Endometrial stromal cells undergoing decidualization down-regulate their properties to produce proinflammatory cytokines in response to interleukin-1 beta via reduced p38 mitogen-activated protein kinase phosphorylation. J Clin Endocrinol Metab 88: 2236-2241, 2003.

62. Comstock IA, Diaz-Gimeno P, Cabanillas S, Bellver J, Sebastian-Leon P, Shah M, Schutt A, Valdes CT, Ruiz-Alonso M, Valbuena D, et al: Does an increased body mass index affect endometrial gene expression patterns in infertile patients? A functional genomics analysis. Fertil Steril 107: 740-748.e2, 2017

63. Tierney EP, Tulac S, Huang ST and Giudice LC: Activation of the protein kinase A pathway in human endometrial stromal cells reveals sequential categorical gene regulation. Physiol Genomics 16: 47-66, 2003.

64. Gellersen B, Brosens IA and Brosens JJ: Decidualization of the human endometrium: Mechanisms, functions, and clinical perspectives. Semin Reprod Med 25: 445-453, 2007.
65. Giudice LC: Endometrium in PCOS: Implantation and predisposition to endocrine CA. Best Pract Res Clin Endocrinol Metab 20: 235-244, 2006.

66. Laird SM, Tuckerman EM, Cork BA, Linjawi S, Blakemore AI and Li TC: A review of immune cells and molecules in women with recurrent miscarriage. Hum Reprod Update 9: 163-174, 2003.

67. Piltonen TT, Chen J, Erikson DW, Spitzer TL, Barragan F, Rabban JT, Huddleston H, Irwin JC and Giudice LC: Mesenchymal stem/progenitors and other endometrial cell types from women with polycystic ovary syndrome (PCOS) display inflammatory and oncogenic potential. J Clin Endocrinol Metab 98: 3765-3775, 2013

68. Habiba MA, Bell SC and Al-Azzawi F: The effect of hormone replacement therapy on the immunoreactive concentrations in the endometrium of oestrogen and progesterone receptor, heat shock protein 27, and human beta-lactoglobulin. Hum Reprod 15: 36-42, 2000. 